Volume 3, Issue 3, July-September 2018, Pages: 269, DOI: http://dx.doi.org/10.19082/ah269

\title{
A PROSPECTIVE STUDY OF ACUTE POISONINGS DURING THE PERIOD (2009-2015) IN THE CHE GUEVARA HOSPITAL, WILAYA DE MOSTAGANEM, ALGERIA
}

Oueld Hennia Chahrazed ${ }^{1}$, Bouabdelli Salah edin ${ }^{2}$, Bouabdelli Fatma ${ }^{3}$, Missounfatiha ${ }^{1,2}$, Djebli Noureddine ${ }^{1,2}$ chahrazedpoupouna@gmail.com

1: Depertement of Biology, Faculty of Nature and Health, University of Abd Hamid IbnBadis, Mostaganem, Algeria.

2: Laboratory of Phytotherapy Apipharmacognosy (LPAP), University of Abd Hamid IbnBadis, Mostaganem, Algeria

\section{TYPE OF ARTICLE: CONFERENCE ABSTRACT}

\begin{abstract}
In incidents of emergency, our hospitals routinely record poisonings or intoxications related to the misuse (or not) of products or foods used by the individual. These intoxications result in symptoms which vary according to the nature of the poisons. The symptoms can be neurological, cardiovascular, respiratory, digestive or renal. Consequences of some intoxications can result in fatality. Our objective is to improve the quantity of information collected by retrospective study related to intoxications from infections in Mostaganem province, Algeria, and to evaluate the risks and to define the actions to be undertaken to prevent serious intoxication in order to better understand which prevention remains the best therapeutic weapon. Our study showed that that percentage of food poisonings was high and with numerous consequences, but the medicaments were inadequate KEYWORDS: Intoxication, Medicaments, Inquiry, Stomach pump, Caustic product
\end{abstract}

\footnotetext{
Abstracts of Third International Conference on Health Sciences and Medical Technologies, October 2018, Tlemcen, Algeria (ICHSMT-18)

(C) 2018 The Authors. This is an open access article under the terms of the Creative Commons Attribution-NonCommercialNoDerivs License, which permits use and distribution in any medium, provided the original work is properly cited, the use is non-commercial and no modifications or adaptations are made.
} 